\title{
Rapid Induction of Ageing Character in Brandy Products - Part II. Influence of Type of Oak
}

\author{
F.P. van Jaarsveld ${ }^{1 *}$, S. Hattingh ${ }^{2}$ and P. Minnaar $^{1}$ \\ (1) ARC Infruitec-Nietvoorbij**, Private Bag X5026, 7599 Stellenbosch, South Africa \\ (2) Department of Medical Physiology, University of Stellenbosch, P. O. Box 19063, Tygerberg, 7505, South Africa
}

Submitted for publication: July 2008

Accepted for publication: October 2008

Key words: Unmatured pot-still brandy, oak type, brandy quality, flavour compounds

\begin{abstract}
As part of a broader study that investigated techniques for the rapid induction of the needed ageing character in brandy products, the effect of oak type on quality and chemical composition of oak wood extracts and matured and unmatured potstill brandy, is reported on. Extracts, prepared from American and French oak chips supplied by a South African cooper, and from commercially obtained oak, and representing different levels of toasting, were added to $70 \%$ (v/v) unmatured pot-still brandy and stored for eight months in glass containers (Schott bottles) at room temperature, or in the case of controls, below $0^{\circ} \mathrm{C}$. Matured and unmatured (control) pot-still brandy samples were analysed for wood-derived congeners by means of HPLC and GC. Although French oak initially yielded better quality products, these effects lost prominence and, after eight months maturation, yielded similar sensory quality to American oak. French oak samples had higher concentrations of wood-derived congeners (including eugenol, the furan derivatives and aromatic aldehydes). However, the American oak generally contained higher concentrations of oak lactones than their French counterparts, with higher proportions of the more sensorially potent cis-form of lactone than its trans-isomer.
\end{abstract}

Over the years wood from many different tree species has been used to manufacture barrels. These species include red oak, chestnut, red or sweet gum, sugar maple, beech, black cherry, acacia karri and mulberry. However, oak (genus Quercus) soon proved to be the most suitable for wine and spirit maturation (Chatonnet, 1999). The oak species most commonly used in barrel-making for brandy and wine maturation are Quercus alba, also known as American oak, which grows in different areas in the United States, $Q$. petraea (Sessile oak) and Q. robur (pedunculate oak), which grow in Europe (Walker, 1996). The most popular wood for barrels is French oak, although oak wood from Eastern Europe and Russia is becoming increasingly available. Wine and spirit producers often prefer certain oak types over others for the maturation of different kinds of alcoholic beverage. The French "appellation d'origine controlée" (AOC) eaux-de-vies, for example, are traditionally matured in barrels fabricated from oak from nearby regions, with cognac almost exclusively matured in oak from the Limousin and Troncais regions (Guymon \& Crowell, 1970). French oak, primarily Limousin, have been used in large quantities for ageing brandy in several countries. These include South Africa, Germany, Mexico and Australia (Guymon \& Crowell, 1970). American whiskies are naturally matured in American oak barrels, while the Scotch whiskey industry has gradually shifted from using predominantly European to American oak barrels (Clyne et al., 1993).

The methods by which barrels are manufactured are not the same, the greatest differences being observed between European and American cooperages. The degree of heating also varies, being mild to moderate in most European cooperages. In contrast, in American cooperages where the barrels are to be used for the production of bourbon or other grain whiskies, heating is usually intense, leading to intense charring (Mosedale \& Puech, 1998). Compared to French (i.e. Tronçais oak, Limousin oak, Gascony oak), Russian and Bulgarian oaks, American oak has the least amount of tannin (Puech, 1984).

Since wood for barrel making varies in price, and because barrels can only be used for maturation purposes a limited number of times, it is evident that the development of alternatives to traditional barrel maturation, such as the use of wood extracts, could have significant economic implications for the wine- and spirit industries. To this effect a number of workers have carried out studies on the different extractable compounds in different types of oak woods (Guymon \& Crowell, 1968; Singleton, 1974; Hacker, 1991; Pérez-Coello et al., 1999; Masson et al., 1995, 2000).

American and French oak chips obtained from a cooper (specially prepared), and from a commercial supplier, and representing different levels of toasting, were compared.

This is the second in a series of articles (Van Jaarsveld et al., 2009). The first article concerned the importance of extracts in brandy maturation, the preparation of oak extracts, the influence of different extraction conditions and mediums, and suppliers of oak chips on chemical and sensory profiles. This paper discusses the effect of oak type on the sensory and chemical profiles of fortified extracts and unmatured and matured pot-still brandy. Toasting is discussed in a separate paper. Interactive aspects of the collected data will be discussed in a subsequent review paper.

\footnotetext{
*Corresponding author: e-mail: VjaarsveldF@arc.agric.za

**The Fruit, Vine and Wine Institute of the Agricultural Research Council
}

Acknowledgements: The authors wish to thank the Agricultural Research Council and the South African Wine Industry (Winetech) for financial support. Special thanks to Marieta van der Rijst for statistical analysis of the data, to Neil Jolly for assistance in the compilation of brandy evaluation scorecards, and to Marais Blom at the Distell Group Limited laboratory for the chemical analysis. 


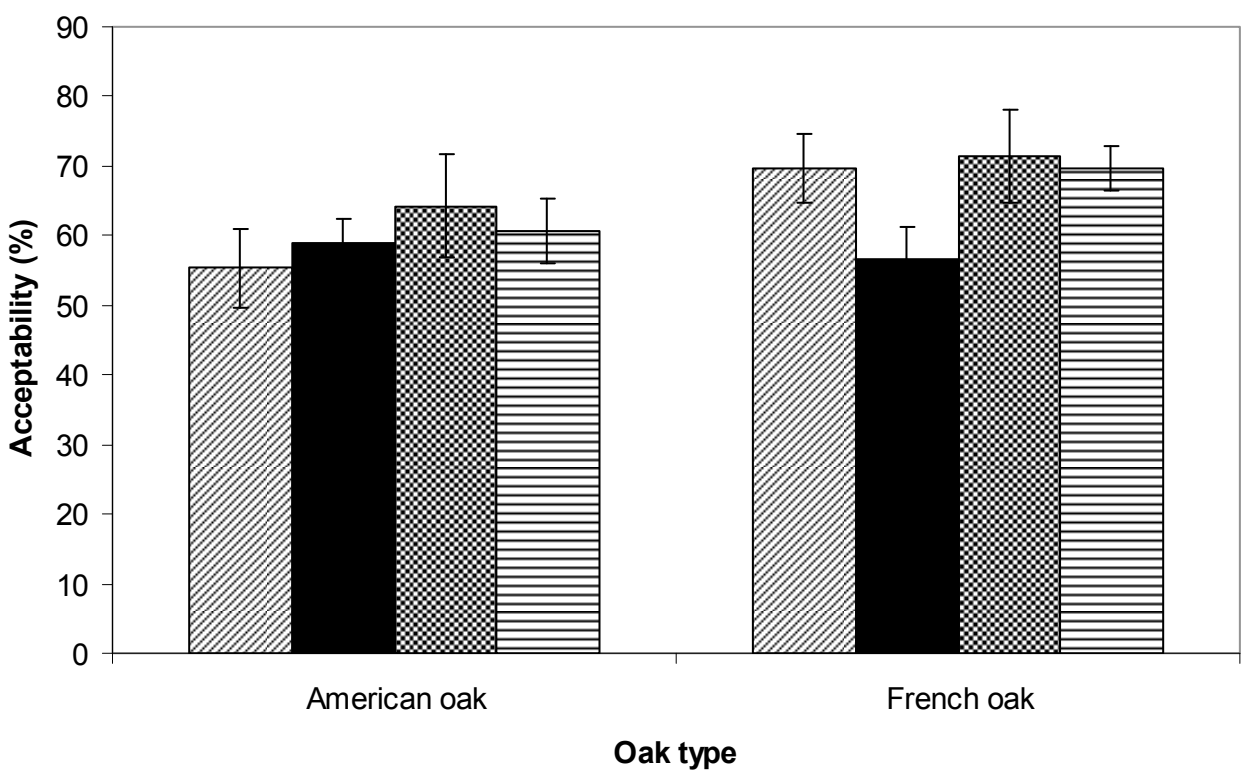

$\square$ Cooper - $45 \% \quad$ Cooper $-65 \% \quad$ Cooper - $85 \% \quad \boxminus$ Cooper - medium

FIGURE 1

Percentage sensory acceptability of oak extracts prepared from chips of different types (American and French) of differently toasted (untoasted, medium and heavy) oak obtained from a cooper and subjected to various treatments. Legend, i.e. cooper $45 \%$, indicate the group subjected to statistical treatment, i.e. only cooper and the $45 \%$ $(\mathrm{v} / \mathrm{v})$ concentration level, with all other treatments nested. Refer to part I in this series for more details regarding various treatments. Error bars represent the standard error of the mean.

\section{MATERIALS AND METHODS}

Materials and methods have been described previously (Van Jaarsveld et al., 2009). Briefly, American and French oak chips, representing different levels of toasting and obtained from a cooper and a commercial supplier, were placed in a water- or a $55 \%(\mathrm{v} / \mathrm{v})$ ethanol medium and boiled under reflux with backflow cooling for $5 \mathrm{~h}$. Open concentration or concentration under vacuum using a Buchi rotavapour followed. Extracts were fortified to $40 \%(\mathrm{v} / \mathrm{v})$. Fortified extracts were added to $70 \%(\mathrm{v} / \mathrm{v})$ unmatured pot-still brandy (procured as one batch) at $60 \mathrm{~mL} / \mathrm{L}$ and stored for eight months in glass containers (Schott bottles) at room temperature, or in the case of controls, below $0^{\circ} \mathrm{C}$. Samples were subjected to sensory and chemical analysis. Fortified $(40 \% \mathrm{v} / \mathrm{v})$ extracts were sensorially evaluated, in duplicate, by a panel of seven judges for acceptability for brandy production and expressed in terms of a simple "yes" or "no response". The number of "yes" scores for each extract evaluated were expressed as a percentage of the total number of evaluations per extract. Pot-still brandy samples were also sensorially evaluated for overall quality by a panel of seven experienced judges. A line method was used, i.e. evaluating the brandy characteristics by marking an unstructured, straight $10 \mathrm{~cm}$ line. The left-hand and right-hand ends of the line were indicated by the terms, "not detectable" and "prominent", respectively.

\section{RESULTS AND DISCUSSION}

From the analysis of variance (ANOVA) of the treatments, oak type (American or French), level of toasting, supplier (i.e. cooper or commercial), type of medium (ethanol or water), concentration type (open or reduced pressure) and concentration level $(45,65$ or $85 \%$ ), with results given in Tables 1 to 5 and Figs 1 to 4 , the significance of the effects of the different treatments and their interactions were determined. Type of oak as a treatment is discussed in this article.

\section{Extracts}

American and French oak have sufficiently different extractables so that it is often possible for an experienced taster to identify which oak was used for brandy or wine ageing (Singleton, 1974). In this study, sensory evaluation (for acceptability only) of fortified oak extracts showed, for both commercial and specially prepared chips from a cooper, that French oak yielded equally or more acceptable extracts than American oak (Fig. 1). Oak species, therefore, certainly influenced the observed differences in the character of wood extracts prepared from them. This agrees with the studies of Singleton (1995) and Francis et al. (1992), who reported that American oak was generally less intense in aroma properties than French oak.

\section{Unmatured pot-still brandy}

Except for cis-oak lactone, French oak generally yielded higher concentrations of volatile wood-derived congeners than American oak (Table 1). The concentrations of less volatile wood-derived congeners in unmatured pot-still brandy prepared from American oak extracts are either similar to $(\mathrm{p} \geq 0.05)$ or significantly lower $(\mathrm{p} \leq 0.05)$ than those from French oak (Table 2).

\section{Eight-month matured pot-still brandy}

Little difference in overall sensory quality ( $p \geq 0.05$ ) was observed between eight-month matured pot-still brandies prepared with extracts using American oak chips and those prepared using French oak chips (Fig. 2). 
TABLE 1

Gas Chromatographic determination of wood-derived congeners in unmatured pot-still brandy prepared from oak (cooper only) extracts.

\begin{tabular}{|c|c|c|c|c|c|c|c|c|c|c|c|}
\hline \multirow[t]{2}{*}{ Type/Treatment } & \multirow[t]{2}{*}{$\mathrm{n}^{*}$} & \multicolumn{10}{|c|}{ Mean $(\mathrm{mg} / \mathrm{L})$} \\
\hline & & Furfural & $\begin{array}{l}\text { 5-Methyl- } \\
\text { furfural }\end{array}$ & & Guaiacol & $\operatorname{trar}$ & Oak lactone & $c i s-\mathbf{O a k}$ & Ictone & $o$-Cresol & Phenol \\
\hline American oak & 12 & $\begin{array}{c}17.618^{\mathrm{b}} \\
(1.893)^{* *}\end{array}$ & $\begin{array}{l}0.798^{\mathrm{a}} \\
(0.342)\end{array}$ & & $\begin{array}{l}0.950^{\mathrm{a}} \\
(0.185)\end{array}$ & & $\mathrm{nd}^{* * *}$ & & & nd & nd \\
\hline \multirow[t]{2}{*}{ French oak } & \multirow[t]{2}{*}{24} & $\begin{array}{l}30.238^{\mathrm{a}} \\
(2.535)\end{array}$ & $\begin{array}{c}0.895^{\mathrm{a}} \\
(0.265)\end{array}$ & & $\begin{array}{c}1.143^{\mathrm{a}} \\
(0.121)\end{array}$ & \multicolumn{2}{|r|}{ nd } & \multicolumn{2}{|c|}{$\begin{array}{c}0.000^{\mathrm{b}} \\
(0.000)\end{array}$} & nd & nd \\
\hline & & \multicolumn{2}{|l|}{ Ethyl guaiacol } & $p$-Cresol & & Eugenol & \multicolumn{2}{|c|}{$\begin{array}{l}\text { 2,6-Dimethoxy- } \\
\text { phenol }\end{array}$} & \multicolumn{2}{|c|}{$\begin{array}{l}\text { 5-Hydroxy- } \\
\text { methyl furfural }\end{array}$} & Vanillin \\
\hline American oak & 12 & $\begin{array}{l}0.000^{\mathrm{a}} \\
(0.000)\end{array}$ & \multicolumn{2}{|r|}{ nd } & & $\begin{array}{c}0.000^{\mathrm{a}} \\
(0.000)\end{array}$ & \multicolumn{2}{|c|}{$\begin{array}{l}29.470^{\mathrm{a}} \\
(1.392)\end{array}$} & \multicolumn{2}{|c|}{$\begin{array}{l}2.640^{\mathrm{a}} \\
(0.557)\end{array}$} & $\begin{array}{c}2.580^{\mathrm{a}} \\
(0.460)\end{array}$ \\
\hline French oak & 24 & $\begin{array}{l}0.004^{\mathrm{a}} \\
(0.004)\end{array}$ & \multicolumn{2}{|r|}{ nd } & & $\begin{array}{l}0.015^{\mathrm{a}} \\
(0.015)\end{array}$ & \multicolumn{2}{|c|}{$\begin{array}{l}33.114^{\mathrm{a}} \\
(0.975)\end{array}$} & \multicolumn{2}{|c|}{$\begin{array}{l}8.281^{\mathrm{a}} \\
(1.728)\end{array}$} & $\begin{array}{c}9.616^{\mathrm{a}} \\
(3.178)\end{array}$ \\
\hline
\end{tabular}

*, Number of evaluations of samples; **, standard error of the mean; ***, not detected. Treatments with the same superscript within columns do not differ significantly $(\mathrm{p} \geq 0.05)$. Data representative of extracts concentrated by $65 \%(\mathrm{v} / \mathrm{v})$.

TABLE 2

High-performance Liquid Chromatographic analysis of unmatured pot-still brandy prepared from oak (cooper only) extracts.

\begin{tabular}{|c|c|c|c|c|c|c|}
\hline Type/Treatment & $n^{*}$ & & & Mean (mg/L) & & \\
\hline & & Gallic acid & Catechin & Vanillic acid & Syringic acid & $p$-Coumaric acid \\
\hline American oak & 12 & $\begin{array}{c}1.230^{\mathrm{b}} \\
(0.102)^{* *}\end{array}$ & $\begin{array}{c}0.389^{b} \\
(0.389)\end{array}$ & $\begin{array}{c}1.006^{\mathrm{b}} \\
(0.290)\end{array}$ & $\begin{array}{l}2.614^{b} \\
(0.562)\end{array}$ & $\begin{array}{c}0.000^{\mathrm{a}} \\
(0.000)\end{array}$ \\
\hline \multirow[t]{2}{*}{ French oak } & 24 & $\begin{array}{l}8.005^{\mathrm{a}} \\
(0.412)\end{array}$ & $\begin{array}{c}4.163^{\mathrm{a}} \\
(1.108)\end{array}$ & $\begin{array}{c}1.460^{\mathrm{a}} \\
(0.246)\end{array}$ & $\begin{array}{l}3.726^{\mathrm{a}} \\
(0.511)\end{array}$ & $\begin{array}{l}0.494^{\mathrm{a}} \\
(0.120)\end{array}$ \\
\hline & & Syringaldehyde & $m$-Coumaric acid & Ellagic acid & Coniferaldehyde & Sinapaldehyde \\
\hline American oak & 12 & $\begin{array}{c}5.844^{\mathrm{a}} \\
(1.310)\end{array}$ & $\begin{array}{c}0.167^{\mathrm{a}} \\
(0.048)\end{array}$ & $\begin{array}{l}15.637^{b} \\
(3.031)\end{array}$ & $\begin{array}{c}7.989^{\mathrm{a}} \\
(2.011)\end{array}$ & $\begin{array}{l}25.832^{\mathrm{a}} \\
(6.887)\end{array}$ \\
\hline French oak & 24 & $\begin{array}{c}5.880^{\mathrm{a}} \\
(0.971)\end{array}$ & $\begin{array}{c}0.271^{\mathrm{a}} \\
(0.065)\end{array}$ & $\begin{array}{l}44.187^{\mathrm{a}} \\
(6.969)\end{array}$ & $\begin{array}{c}8.023^{\mathrm{a}} \\
(1.374)\end{array}$ & $\begin{array}{l}31.000^{\mathrm{a}} \\
(4.605)\end{array}$ \\
\hline
\end{tabular}

*, Number of evaluations of samples; **, standard error of the mean. Treatments with the same superscript within columns do not differ significantly (p $\geq 0.05$ ). Data representative of extracts concentrated by $65 \%(\mathrm{v} / \mathrm{v})$.

French oak was described as more "woody" and "toasted" than American oak (Fig. 2). As reported by Sefton et al. (1993), the differences in sensory quality between American and French oak reflected in the concentrations of oak components in the corresponding oak extracts and pot-still brandies (Tables 3 and 4).

Except for trans- and cis-oak lactones, the concentrations of volatile and less volatile components were generally higher in eight-month matured pot-still brandies prepared from French oak as compared to American oak (Tables 3 and 4). European oak is known to be higher in extractables than American oak, but with the same substances (Singleton, 1974, 1995). The total impact of higher concentrations of wood-derived congeners, but lower concentrations of the important flavour compounds cis- and trans-oak lactones in French samples, would probably explain the minor differences $(p \geq 0.05)$ in quality between French and American samples aged in glass containers for eight months. Unmatured pot-still brandies prepared with French oak extracts were initially sensorially more favourable compared to their American oak counterparts. Differences in eight-month matured pot-still brandies, however, were less conspicuous. The most 


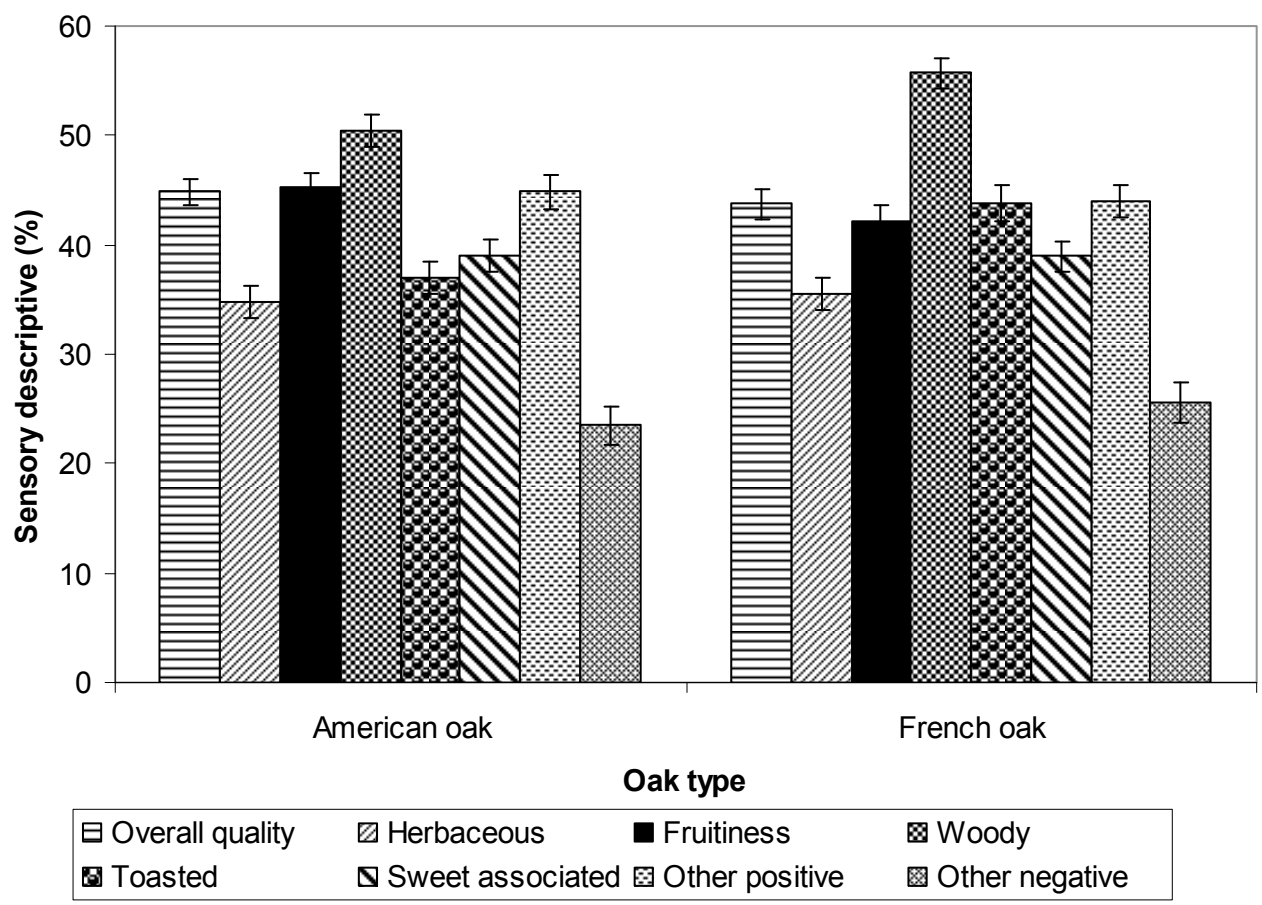

FIGURE 2

Overall sensory quality and other sensory descriptives of eight-month matured pot-still brandy from oak extracts prepared with chips of different types (American and French) of differently toasted oak obtained from a cooper and subjected to various treatments. Only the $65 \%$ (v/v) concentration level was considered in the statistical evaluation. Refer to part I in this series for more detail regarding the various treatments. Error bars represent the standard error of the mean.

\section{TABLE 3}

Gas Chromatographic analysis of eight month matured pot-still brandy prepared using oak extracts from different species of oak chips specially prepared by a cooper.

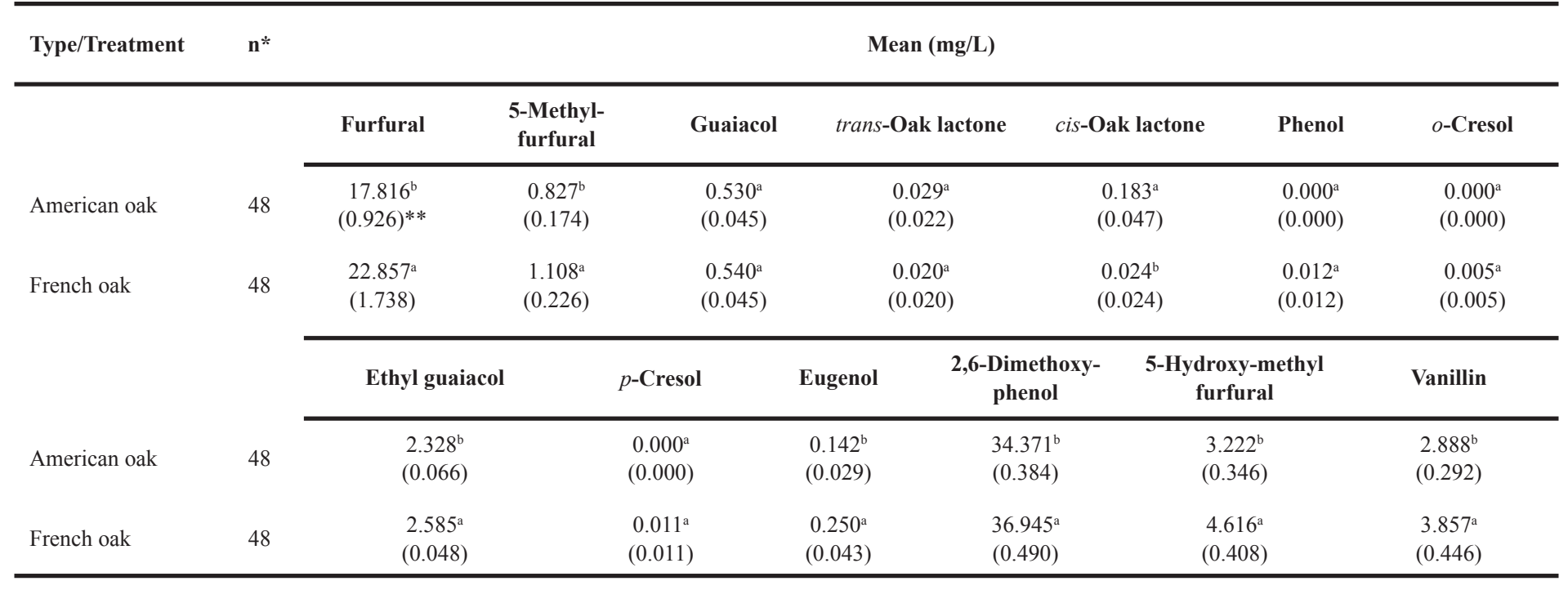

*, Number of evaluations of samples; **, standard error of the mean. Treatments with the same superscript within columns do not differ significantly ( $\mathrm{p} \geq 0.05$ ). Data representative of extracts concentrated by $65 \%(\mathrm{v} / \mathrm{v})$

plausible explanation for this phenomenon is the increase in, or rather, appearance, of trans-oak lactone in eight-month matured pot-still brandies (not observed in unmatured preparations) and significantly higher quantities of cis-oak lactone in American oak preparations as compared to their French oak counterparts. Although analysis revealed differences in concentrations of wood-derived congeners, tasters were unable to detect significant differences between eight-month old pot-still brandies prepared with American oak from those prepared using French oak extracts in this study. In addition to the concentration and detection threshold limits of the individual wood-imparted compounds, their synergistic actions and long term stability are important factors impacting on oak aroma and taste (Singleton, 1995). Other authors have also reported sensory panel difference tests showing 


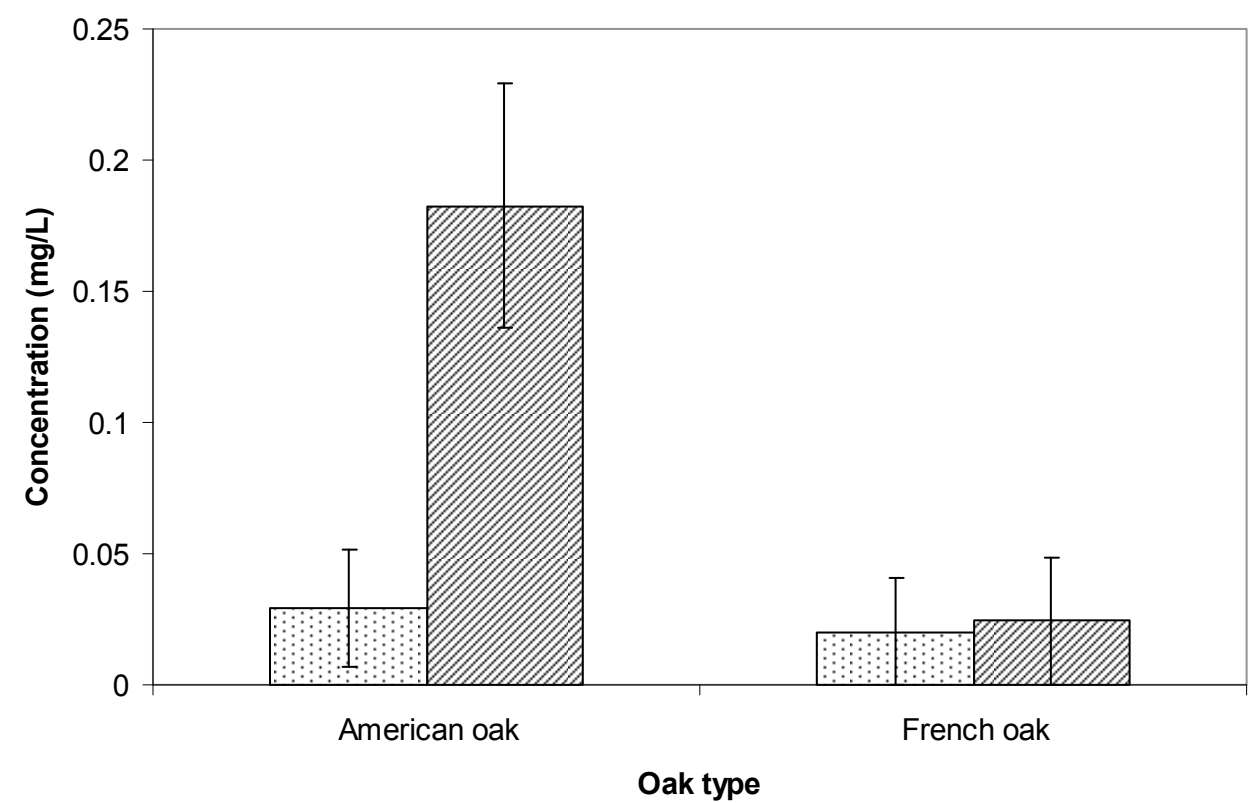

FIGURE 3

GC-determined concentration of trans-oak lactone and cis-oak lactone in eight-month matured pot-still brandy samples prepared with extracts representing chips of different types (American and French) of differently toasted oak obtained from cooper and subjected to various treatments. Only the $65 \%$ (v/v) concentration level was considered in the statistical evaluation. Refer to part I in this series for more detail regarding the various treatments. Error bars represent the standard error of the mean.

\section{TABLE 4}

High-performance Liquid Chromatographic analysis of eight-month matured pot-still brandy prepared from oak (cooper only) extracts.

\begin{tabular}{|c|c|c|c|c|c|c|c|c|}
\hline \multirow[t]{2}{*}{ Type/Treatment } & \multirow[t]{2}{*}{$n *$} & \multicolumn{7}{|c|}{ Mean (mg/L) } \\
\hline & & $\begin{array}{l}\text { Gallic } \\
\text { acid }\end{array}$ & $\begin{array}{c}\text { Proto-catachuic } \\
\text { acid }\end{array}$ & $\begin{array}{l}p \text {-Hydroxy- } \\
\text { benzoic acid }\end{array}$ & Catechin & $\begin{array}{l}\text { Vanillic } \\
\text { acid }\end{array}$ & $\begin{array}{l}\text { Syringic } \\
\text { acid }\end{array}$ & $\begin{array}{c}p \text {-Coumaric } \\
\text { acid }\end{array}$ \\
\hline American oak & 48 & $\begin{array}{c}0.863^{\mathrm{b}} \\
(0.075)^{* *}\end{array}$ & $\begin{array}{c}0.574^{\mathrm{a}} \\
(0.157)\end{array}$ & $\begin{array}{c}0.055^{\mathrm{b}} \\
(0.027)\end{array}$ & $\begin{array}{c}1.655^{\mathrm{a}} \\
(0.909)\end{array}$ & $\begin{array}{c}0.978^{\mathrm{b}} \\
(0.159)\end{array}$ & $\begin{array}{c}2.398^{\mathrm{b}} \\
(0.284)\end{array}$ & $\begin{array}{c}0.000^{\mathrm{a}} \\
(0.000)\end{array}$ \\
\hline \multirow[t]{2}{*}{ French oak } & 48 & $\begin{array}{c}7.380^{\mathrm{a}} \\
(0.320)\end{array}$ & $\begin{array}{c}0.410^{\mathrm{b}} \\
(0.130)\end{array}$ & $\begin{array}{c}0.736^{\mathrm{a}} \\
(0.159)\end{array}$ & $\begin{array}{c}0.750^{\mathrm{b}} \\
(0.218)\end{array}$ & $\begin{array}{c}1.864^{\mathrm{a}} \\
(0.196)\end{array}$ & $\begin{array}{l}3.081^{\mathrm{a}} \\
(0.376)\end{array}$ & $\begin{array}{c}0.014^{\mathrm{a}} \\
(0.010)\end{array}$ \\
\hline & & Syringaldehyde & \multicolumn{2}{|c|}{$m$-Coumaric acid } & Ellagic acid & \multicolumn{2}{|c|}{ Coniferaldehyde } & Sinapaldehyde \\
\hline American oak & 48 & $\begin{array}{c}7.753^{\mathrm{b}} \\
(0.854)\end{array}$ & \multicolumn{2}{|c|}{$\begin{array}{c}0.000^{\mathrm{a}} \\
(0.000)\end{array}$} & $\begin{array}{c}4.743^{\mathrm{a}} \\
(0.625)\end{array}$ & \multicolumn{2}{|c|}{$\begin{array}{l}14.161^{\mathrm{b}} \\
(1.366)\end{array}$} & $\begin{array}{l}14.167^{\mathrm{b}} \\
(1.921)\end{array}$ \\
\hline French oak & 48 & $\begin{array}{l}10.610^{\mathrm{a}} \\
(1.118)\end{array}$ & \multicolumn{2}{|c|}{$\begin{array}{c}0.043^{\mathrm{a}} \\
(0.015)\end{array}$} & $\begin{array}{l}4.859^{\mathrm{a}} \\
(0.606)\end{array}$ & \multicolumn{2}{|c|}{$\begin{array}{l}42.188^{a} \\
(4.774)\end{array}$} & $\begin{array}{l}16.493^{a} \\
(2.313)\end{array}$ \\
\hline
\end{tabular}

*, number of evaluations of samples; **, standard error of the mean. Treatments with the same superscript within columns do not differ significantly ( $\mathrm{p} \geq 0.05$ ). Data representative of extracts concentrated by $65 \%(\mathrm{v} / \mathrm{v})$.

little to no difference between the two types of oak (Francis et al., 1992), notwithstanding differences in the concentrations of important oak compounds (Gawel et al., 2002). Most studies, however, report on the ability to sensorially differentiate between American and French oak (Guymon \& Crowell, 1970; Francis et al., 1992; Singleton, 1995) with tasters being able to sensorially differentiate between the use of American from French barrels up to the third filling. Guymon \& Crowell (1970) reported Limousin- aged brandy to be milder in oak odour and aroma, more agreeable and subtle, and softer in taste than the American oak counterpart.

\section{General}

The concentrations of sensorially important compounds vary between French and American oak. American oak contains higher concentrations of oak lactones than French oak (Otsuka et al., 1974; Anonymous, 1995; Chatonnet \& Dubourdieu, 1998; 


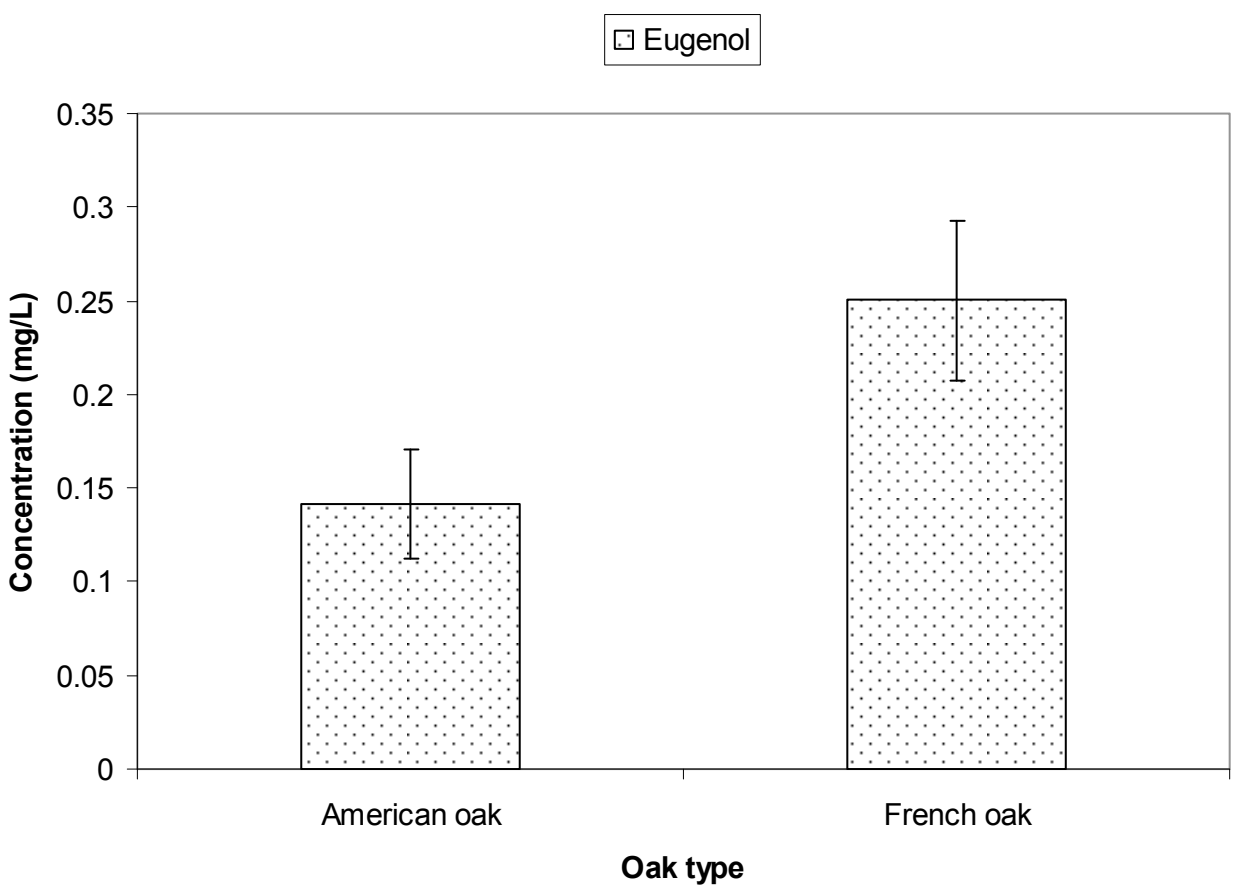

FIGURE 4

GC-determined concentration of eugenol in eight-month matured brandy samples prepared with extracts from chips of different types (American and French) of differently toasted oak obtained from a cooper and subjected to various treatments. Only the $65 \%$ (v/v) concentration level was considered in the statistical evaluation. Refer to part I in this series for more detail regarding the various treatments. Error bars represent the standard error of the mean.

Chatonnet, 1999; Gawel et al., 2002; Spillman et al., 2004). This difference is reflected in unmatured and matured pot-still brandies in this study, where those prepared with American oak were generally characterised by higher concentrations of oak lactones than those prepared using French oak (Tables 1, 3; Fig. 3). In addition, and similar to reports in literature (Spillman et al., 2004), higher proportions of the sensorially more potent cis- form of oak lactone are generally present in American and French oakprepared pot-still brandies compared to its trans-isomer (Tables 1, 3 ; Fig. 3). Singleton (1995) reported a $77 \%$ cis to $23 \%$ trans ratio for European oak. Otsuka et al. (1974) reported greater amounts of trans- than cis-oak lactone. Also, as reported in literature (Singleton, 1995; Chatonnet \& Dubourdieu, 1998; Hale et al., 1999), American white oak was found to be richer in cis-methyloctalactone (cis-oak lactone) than its European counterparts (Tables 1 and 3; Fig. 3). American oak, due to its higher content of cis/trans isomers of $\beta$-methyl- $\gamma$-octalactone (oak lactone), has greater aromatic potential than European oak. This factor, together with its lower content of extractable polyphenols, makes American oak easier to identify (Chatonnet \& Dubourdieu, 1998; Mosedale \& Puech, 1998). Studies (Godden et al., 1999) have shown that the source of the oak is more important and determining than the nature of the fermentation treatment. Variation in oak lactone, however, is not only influenced by the source of the oak, but also by other factors such as location/origin, with some authors (Sefton \& Spillman, 1995) reporting opposite trends, i.e. finding American oak to be poor and French oak to be rich in cis-oak lactone. In previous studies performed at the ARC Infruitec-Nietvoorbij, using a different method of extraction, higher concentrations of cis-oak lactone, and lower concentrations of trans-oak lactone were found in French oak toasted at $230^{\circ} \mathrm{C}$ as compared to American oak toasted at $220^{\circ} \mathrm{C}$. The aroma associated with oak

\section{TABLE 5}

Aromatic acid/aldehyde quotients in matured pot-still brandies.

\begin{tabular}{|c|c|c|c|c|c|}
\hline \multirow[t]{2}{*}{ Supplier } & \multirow[t]{2}{*}{ Type of oak } & \multirow[t]{2}{*}{$\mathbf{n}^{*}$} & \multicolumn{3}{|c|}{$\begin{array}{c}\text { Syringaldehyde: } \\
\text { Vanillin ratio }\end{array}$} \\
\hline & & & Minimum & Maximum & Mean \\
\hline \multirow[t]{11}{*}{ Cooper } & American oak & 36 & 0.30 & 4.19 & $2.47(0.15)^{* *}$ \\
\hline & French oak & 37 & 0.00 & 6.39 & $2.76(0.22)$ \\
\hline & & & \multicolumn{3}{|c|}{ Gallic acid: Vanillin ratio } \\
\hline & American oak & 36 & 0.01 & 0.77 & $0.25(0.03)$ \\
\hline & French oak & 37 & 0.03 & 4.04 & $1.65(0.15)$ \\
\hline & & & \multicolumn{3}{|c|}{ Vanillic acid: Vanillin ratio } \\
\hline & American oak & 36 & 0.00 & 1.01 & $0.32(0.04)$ \\
\hline & French oak & 37 & 0.00 & 1.83 & $0.38(0.06)$ \\
\hline & & & \multicolumn{3}{|c|}{ Syringic: Vanillic acid ratio } \\
\hline & American oak & 32 & 0.96 & 9.25 & $3.47(0.45)$ \\
\hline & French oak & 43 & 0.00 & 5.52 & $2.26(0.26)$ \\
\hline
\end{tabular}

*, Number of evaluations of samples; **, standard error of the mean. Data representative of brandies prepared with extracts from either French or American oak chips of different toast levels obtained from a cooper and concentrated by $65 \%(\mathrm{v} / \mathrm{v})$.

lactone has been considered to be desirable by most assessors (Suomalainen et al., 1974; Sefton et al., 1993). Nevertheless, the quantity of extractable methyl-octalactones, particularly the cisisomer, can sometimes be excessive in American oak. Excessive concentrations of lactones may give rise to a resinous odour that 
masks the fruity character, with possible negative effects on aroma (Chatonnet \& Dubourdieu, 1998; Sauvageot \& Feuillat, 1999). This may partly explain why, in this study, American oak preparations, in spite of higher concentrations of methyloctalactone, fared similarly to matured pot-still brandies prepared with French oak (Fig. 2). Although the concentrations of transoak lactone in this study (Tables $1 \& 3$ ) were generally below the reported thresholds of $0.8 \mathrm{mg} / \mathrm{L}, 0.067 \mathrm{mg} / \mathrm{L}$ and traces to 0.68 mg/L (Otsuka et al., 1974; Singleton, 1995), cis-oak lactone on the other hand, generally in the case of American oak-prepared and/or commercial samples, was found at concentrations above the reported thresholds of $0.07 \mathrm{mg} / \mathrm{L}, 0.79 \mathrm{mg} / \mathrm{L}, 0.092 \mathrm{mg} / \mathrm{L}$ and 0.13 to $1.54 \mathrm{mg} / \mathrm{L}$ in brandies and commercial products of different ages (Otsuka et al., 1974; Singleton, 1995; Mosedale \& Puech, 1998). In addition, European cooperage oak samples are reported to have $161 \%$ of the extractable solids of North American samples and $154 \%$ of the phenol per unit of extractable solids, whereas American oak contributed more oak flavour to wine per unit of extract (Singleton, 1974).

As was found by Sefton et al. (1993), Pérez-Coello et al. (1999) and Spillman et al. (2004), higher concentrations of eugenol were generally found in samples prepared with French oak than in those prepared with American oak (Tables 1 and 3; Fig. 4). Singleton (1995) reported American oak to contain higher concentrations of eugenol than French oak. The furan derivatives, i.e. furfural were present in lower quantities in American than French oak extracts (Tables 1 and 3), which is in agreement with the results reported by other authors. Guymon \& Crowell (1970), however, reported lower concentrations of furfural in Limousin barrel-aged brandy. In this study, quantities of aromatic aldehydes in pot-still brandies prepared from American and French oak, coniferaldhyde, synapaldehyde and syringaldehyde are the most abundant, with vanillin present in lesser quantities. Higher syringaldehyde than vanillin contents in liquid and powder oak extracts, wine spirit extracts, and spirits aged in oak barrels were also reported by other authors (Puech, 1988; Giménez Martínez et al., 2001). All compounds were present in higher concentrations in French than American oak-prepared samples, including the aromatic acids syringic acid and vanillic acid (Tables 1 to 4). Guymon \& Crowell (1970) reported that American oak contains more of these compounds than French oaks. Suomalainen \& Nykänen (1972) reported syringaldehyde and vanillin to be generally the most abundant, with coniferaldehyde often equally abundant, but sinapaldehyde present in very small amounts, especially in French oak. Consideration must always be given to the fact that furan concentrations, and furan derivative concentrations, may increase considerably during heat treatment, and that observed differences between American and French oak may also be due to possible differences in heat treatments. In this study the syringic acid:vanillic aromatic acid ratios of unmatured pot-still brandies from different suppliers prepared with American and French oak chips ranged from 2.4 to 2.6 and from 2.0 to 2.3 , respectively. The ratios of these lignin-derived aromatic acids in eight-month matured pot-still brandies are shown in Table 5. Generally the maximum and average ratios were higher in French oak as opposed to American oak samples, except for the syringic acid:vanillic acid ratio (Table 5). The type of wood is known to influence the gallic acid:vanillin ratio in brandies; the gallic acid:vanillin ratio has been used in studying the quality of brandies (Giménez Martínez et al., 2001). Puech (1988) reported syringic acid:vanillic acid ratios of 1.5 for Armagnac brandies, 1.1 to 7.17 for liquid wood extracts, and 1.6 to 3.5 for extracts in powder form.

\section{CONCLUSIONS}

Although French oak initially yielded better quality products, these effects lost prominence, yielding similar sensory quality to American oak after eight months maturation. The differences in sensory quality between American and French oak reflected in the concentrations of oak components in the corresponding oak extracts and pot-still brandies. French oak samples generally had higher concentrations of wood-derived congeners (including eugenol, the furan derivatives and aromatic aldehydes). American oak, however, generally contained higher concentrations of oak lactones than their French counterparts. The sensorially more potent $c i s$-form was generally present in higher proportions than the trans-isomer. Although recommendations regarding single treatments can be made, it must be borne in mind that it is not always a single treatment, but a combination of various practices, that yield the best quality products.

\section{LITERATURE CITED}

Anonymous 1995. American oak. Wynboer, September, 52.

Chatonnet, P., 1999. Volatile and odoriferous compounds in barrel-aged wines: impact of cooperage techniques and aging conditions. In: Waterhouse, A.L. \& Ebeler, S.E., (eds). Chemistry of Wine Flavour. 1999 - ACS Symposium Series no. 714. American Chemical Society, Washington D.C. pp. 180-207.

Chatonnet, P. \& Dubourdieu, D., 1998. Comparative study of the characteristics of American white oak (Quercus alba) and European oak (Quercus petraea and Q. robur) for production of barrels used in barrel ageing wines. Am. J. Enol. Vitic. $49,79-85$.

Clyne, J., Conner, J.M., Paterson, A. \& Piggott, J.R., 1993. The effect of cask charring on Scotch whisky maturation. Int. J. Food Sci. Technol. 28, 69-81.

Francis, I.J., Sefton, M.A. \& Williams, P.J., 1992. A Study by sensory descriptive analysis of the effects of oak origin, seasoning, and heating on the aromas of oak model wine extracts. Am. J. Enol. Vitic. 43, 20-30.

Gawel, R., Royal, T. \& Leske, P., 2002. The effect of different oak types on the sensory properties of a Chardonnay wine. Aust. NZ. Grapegrower \& Winemaker, 22-24.

Giménez Martínez, R., López García De La Serrana, H., Villalón Mir, M., Navaro Alarcón, M., Olalla Herrera, M., Cabrera Vique, C. \& López Martínez, M.C., 2001. Study of vanillin syringaldehyde and gallic acid content in oak wood and wine spirits mixtures: Influence of heat treatment and chip size. J. Wine Res. 12, 175-182.

Godden, P.W., Pollnitz, A.P., Osicka, S., Sykes, M., Liacopoulos, D., Pardon, K.H., Spillman, P.J., Gawel, R., Jones, G.P., Skluoumounis, G.K. \& Sefton, M.A. 1999. Measuring desirable oakwood components in wine. In: Blair, R.J., Sas, A.N., Hayes, P.F. \& Høj, P.B. (eds). Proc. 10 ${ }^{\text {th }}$ Australian Wine Ind. Tech. Conf., 2-5 August 1998, Sydney, New South Wales, Australia. pp. 121-124.

Guymon, J.F. \& Crowell, E.A., 1968. Separation of vanillin, syringaldehyde, and other aromatic compounds in the extracts of French and American oak woods by brandy and aqueous alcohol solutions. Qual. Plant. Mater. Veg. 16, 320-333.

Guymon, J.F. \& Crowell, E.A., 1970. Some comparisons of American and French oak cooperage. Wines \& Vines 51, 23-25.

Hacker, W.F., 1991. Die houtvat - sy eienskappe en invloed op wyn. Wynboer, October, 6.

Hale, M.D., McCafferty, K., Larmie, E., Newton, J. \& Swan, J.S., 1999. The influence of oak seasoning and toasting parameters on the composition and quality of wine. Am. J. Enol. Vitic. 50, 495-502.

Masson, E., Baumes, R., Le Guernevé, C. \& Puech, J.-L., 2000. Identification of a precursor of b-methyl-g-octalactone in the wood of sessile oak (Quercus petraea (Matt.) Liebl.). J. Agric. Food Chem. 48, 4306-4309.

Masson, G., Guichard, E., Fournier, N. \& Puech, J.-L., 1995. Stereoisomers of 
b-methyl-g-octalactone. II. Contents in the wood of French (Quercus robur and Quercus petraea) and American (Quercus alba) oaks. Am. J. Enol. Vitic. 46, 424428.

Mosedale, J.R. \& Puech, J-L., 1998. Wood maturation of distilled beverages. Trends in Food Sci. Technol. 9, 95-101.

Otsuka, K-I., Zenibayashi, Y., Itoh, M. \& Totsuka, A., 1974. Presence and significance of two diastereomers of $\beta$-methyl- $\gamma$-octalactone in aged distilled liquors. Agr. Biol. Chem. 38, 485-490.

Pérez-Coello, M.S., Sanz, J. \& Cabezudo, M.D., 1999. Determination of volatile compounds in hydroalcoholic extracts of French and American oak wood. Am. J. Enol. Vitic. 50, 162-165.

Puech, J-L., 1984. Characteristics of oak wood and Biochemical aspects of Armagnac aging. Am. J. Enol. Vitic. 35, 77-81.

Puech, J-L., 1988. Phenolic compounds in oak wood extracts used in the ageing of brandies. J. Sci. Food Agric. 42, 165-172.

Sauvageot, F. \& Feuillat, F., 1999. The influence of oak wood (Ouercus robur L., Q. petraea Liebl.) on the flavor of Burgundy Pinot noir. An examination of variation among individual trees. Am. J. Enol. Vitic. 50, 447-455.

Sefton, M.A., Spillman, P.J., Pocock, K.F., Francis, L.L. \& Williams, P.J., 1993. The influence of oak origin, seasoning, and other industry practices on the sensory characteristics and composition of oak extracts and barrel-aged white wines. Aust. Grapegrower Winemaker No. 355, July, 17-25.
Sefton, M.A. \& Spillman, P.J., 1995. The influences of oak, coopering heat and microbial activity on oak-derived wine aroma. In: Stockley, C.S., Sas, A.N., Johnstone, R.S. \& Lee, T.H. (eds.). Proc. $9^{\text {th }}$ Aust. Wine Ind. Tech. Conf., 16-19 July 1995, Adelaide, South Australia. pp. 66-71.

Singleton, V.L., 1974. Some aspects of the wooden container as a factor in wine maturation. In: Dinsmoor Webb, A. (ed). Chemistry of Wine Making, Advances in Chemistry Series, 137. American Chemical Society, Washington D.C. pp. 254277.

Singleton, V.L., 1995. Maturation of wines and spirits: comparisons, facts, and hypothesis. Am. J. Enol. Vitic. 46, 98-115.

Spillman, P.J., Sefton, M.A. \& Gawel, R., 2004. The effect of oak wood source, location of seasoning and cooperage on the composition of volatile compounds in oak-matured wines. Aust. J. Grape Wine Res. 10, 216-226.

Suomalainen, H. \& Nykänen, L., 1972. Formation of aroma compounds in alcoholic beverages. Wallerst. Lab. Comm., XXXV, 185-198.

Suomalainen, H., Nykänen, L. \& Eriksson, K., 1974. Composition and consumption of alcoholic beverages - a review. Am. J. Enol. Vitic. 25, 179-186.

Van Jaarsveld, F.P., Minnaar, P., Blom, M. \& Hattingh, S., 2009. Rapid induction of ageing character in brandy products - Part I. Effects of extraction media and preparation conditions. S. Afr. J. Enol. Vitic. 30, 1-15.

Walker, L.1996. The mystique of oak chips. Wines \& Vines, September, 16-18 